\title{
Enhancing the Language Literacy Skills of Children with Specific Learning Difficulties; A Review on the Use of Technology and the Application of Innovative Teaching Methods
}

\author{
Asimina Riga \\ Georgia Andreou \\ Fotini Anastassiou \\ University of Thessaly / Hellenic Open University
}

doi: 10.19044/ejes.v4no3a2 URL:http://dx.doi.org/10.19044/ejes.v4no3a2

\begin{abstract}
The cultivation of language literacy has been one of the main goals of the educational process. However, students with Specific Learning Difficulties (SLD) are usually unable to keep up with the rest of their class as they face difficulties in their reading and later in their written speech skills. The aim of this paper is to present a brief literature review of teaching strategies and the applications and software that can enhance the basic competences and skills directly linked to the language literacy of students with SLD.

The use of new technologies for the language education of children with SLD is a great advantage because the teacher is able to apply innovative teaching methods. These methods contribute to the reduction of attention and memory problems and to the development of the necessary language skills of students with SLD by enhancing their interaction and collaborative learning. The use of technology can contribute to the appropriate adaptation of curricula, to the creation of multiple teaching activities and to the reduction of the attention and perception difficulties of these students.
\end{abstract}

Keywords: Specific Learning Difficulties, language literacy, new technologies.

\section{Introduction}

The term "literacy" is used by experts to refer not only to the technique of reading and writing, but also to the ability of the individual to understand, interpret and critically deal with different types of speech, to produce a variety of speech, to understand and negotiate the meaning of messages within their social context and generally to control their life and the environment through 
written discourse (Hatzisavvidis, 2010). The aim of language literacy is therefore to understand and produce spoken and written language, and the communication and cultivation of language skills (Matsagouras, 2007).

However, pupils with Specific Learning Difficulties usually deviate from the level of their class as they encounter difficulties, which are initially located in reading and later in writing too. Reading difficulties arise from different deficits that the students may show, and so different pedagogical actions are required, according to the ones needed for students with deficits in visual or audiophonic processing. Reading difficulties are usually accompanied by difficulties in writing, which may take the form of mistakes, such as reversals, confusion of letters, omission or addition of letters, etc. Curriculum can be customized at different levels in order to create an educational environment for different children with different needs. For example, the content of the lessons, the adaptation of teaching strategies and, in particular, the introduction of new forms of technology that meet the particular needs of pupils with an SLD can be changed (Pozzi, 2011). The use of technology can help teachers to provide students with SLD the much needed personalization of learning activities, the immediate feedback as well as the systematic and continuous practice (Pozzi, 2011).

A number of studies have demonstrated that computer usage is beneficial when used in general education. However, the main goal of this brief review is to investigate how positive are the effects of technology on the language literacy skills of children with SLD, so as to fill the gap in the current literature and to spur further research.

\section{The use of technology for the improvement of the language literacy of children with learning difficulties.}

The use of technology can contribute to the appropriate curriculum adaptation, since many teaching activities can be used to mitigate the basic difficulties of students such as attention and perception difficulties so as to cater for their need to personalize exercises, to receive immediate feedback or to perform exercises systematically.

Educational technology programs include training programs, simulations, games, authoring programs, problem solving programs and strategy teaching programs (Panteliadou \& Argyropoulos, 2011). At the same time, technology can contribute to the frequent collection and recording of data from a curriculum-based assessment as well as in teaching, while at the same time it can support the application of new teaching methods in a variety of subject areas (Dawson, Heathcote \& Poole, 2010).

Findings suggest that the use of high quality interactive e-storybooks may support emergent literacy development through the use of scaffolding, thus, supporting vocabulary development, engagement, and comprehension of 
the story (Moody, 2010). E-storybooks or Electronic books are defined as an electronic form of a book with features similar to those of a traditional print book including pages that "turn," and digital features that can assist the reader such as word pronunciations, text highlighting, and text-to speech options, and hypermedia (e.g., video, animations, and sound) (Adam \& Wild, 1997; Horney \& Anderson Inman, 1999; Korat \& Shamir, 2004).

More specifically, E-storybooks are widely used with students who are beginning to learn to read or diagnosed with reading disabilities (Zucker, Moody, \& McKenna, 2009). Their content may be cut off, detached or stored for later use (Vassiliou \& Rowley, 2008). At the same time, specific adjustments such as changing the type or font size and screen brightness make reading easier and more efficient. Indeed, according to Tzivinikou (2015), the ebook with its features makes it more feasible to design a course in a more spherical way and is included in the list of adaptations and differentiations proposed for pupils with special educational needs.

It is a fact that students with difficulties in their written speech due to motor problems, benefit in particular from the learning of systematic typing. Indeed, according to Mponti (2013), typing of sentences or texts on the computer contributes to the development of all the individual factors involved in the written discourse, such as reading ability, phonological competence which in turn are related to spelling and writing. This is because the recording of a word on the computer is preceded by its letter-to-letter analysis, the preintonation of its letters, spacing between words, spelling, as well as the grammatical and editorial correctness of words.

Moreover, it is useful to use training programs through play or through exercises that can motivate these children to practice and improve their spelling. In fact, through typing, students see the word, listen to it, and then write it; on the one hand, they learn exemplary finger movements that help them remember the correct spelling, and on the other hand they are being helped to connect the sound with the graph, improving the phonological competence of the students (Hasselbring \& Candyce, 2000; Kumar, Paek \& Lee, 2012).

There are language learning applications with a virtual tutor for language learning and speech training. Several advantages of utilizing a computer-animated agent as a language tutor are clear, including the popularity of computers and embodied conversational agents. Computerbased instruction is emerging as a prevalent method to train and develop vocabulary knowledge for individuals with special needs (Massaro, 2004).

Also, it is possible to facilitate the connection of sounds and graphs through computer programs that read the texts while also guiding the reader by highlighting on the screen each letter or word spoken. This method can help with reading decoding problems (Kumar, Paek \& Lee, 2012). At the same 
time, some programs allow the user to click on an unknown word in order to hear its synonym or its explanation, thus improving and enriching their vocabulary. However, the most important element of these programs is the fact that they present the reading process in small steps as well as that they give students an incentive to read (Kumar, Paek \& Lee, 2012).

\section{The use of visual aids and concept maps in class as useful tools for the enhancement of the students' literacy abilities.}

In addition, the use of visual aids, graphemes and concept maps enhances the understanding and strategic thinking of students, who can have direct access to vocabulary or concept explanations as well as other useful information (Castellani \& Jeffs, 2001). Indeed, concept maps are designed so that both students and teachers can point out the key ideas to which they should focus their attention, therefore avoiding any stimuli that could potentially distract them (Zaid, 2011). This method can help students a great deal; especially those who show attention difficulties, and can improve their ability to produce written speech by exercising the use of the conceptual map as a metacognitive tool (Novak, 2010).

More specifically, the concept map is a practical way of taking notes when delivering a lesson, as well as a tool for organizing their ideas during the phase before they begin writing. Planning, which is the initial writing phase of a text, increases the pupil's ability to perform mental work and contributes to the student's best performance when she reaches the writing stage. Moreover, the use of the Internet promotes the creation of a social reference framework for students with Learning Difficulties (Stanford \& Siders, 2001). Internet-based videos enable connectivity, efficiency, interactivity and flexibility in teaching, by involving teachers and learners in activities that encourage the cultivation of communication skills and the presentation of ideas and information aiming to meet a variety of needs. In addition, as a source of information and means of communication, it is ranked as one of the powerful educational tool that facilitates access to learning, promotes and changes pedagogical practices by making use of sound, image and multimodal text (Cruse, 2007).

Using Internet video in education releases teaching and learning from the physical boundaries of the classroom and nullifies access time to learning resources. It also extends the experiences of children and achieves fundamental and qualitative changes in the nature of learning and teaching in a wide range of subjects.

\section{Conclusion}

Making use of ICT abilities can make a significant contribution to upgrading the nature and form of knowledge provided to people with learning 
difficulties. In addition, their use brings Special Education closer to society and to the modern approaches of teaching and pedagogical research. The current bibliography includes several papers that present mainly positive results from the use of technologies both in general and in special education towards the achievement of specific cognitive, social and emotional goals (Keenngwe, Schnellert \& Mills, 2012; Walker, Rummel \& Koedinger, 2011).

\section{References:}

Adam, N. \& Wild, M. (1997) Applying CD-ROM interactive storybooks to learning to read. Journal of Computer Assisted Learning, Vol. 13, p. 119-132. Castellani, J. \& Jeffs, T. (2001). Emerging Reading and Writing Strategies Using Technology. TEACHING Exceptional Children, 33 (5), 60-67.

Cruse, E. (2007). Using educational video in the classroom: Theory, research and practice. Wynnewood, PA: Library Video Company. Available: http://www.libraryvideo.com/articles/article26.asp

Dawson, S., Heathcote, L., \& Poole, G. (2010) "Harnessing ICT potential: The adoption and analysis of ICT systems for enhancing the student learning experience", International Journal of Educational Management, Vol. 24 Iss: 2, pp. $116-128$

Hasselbring, T., \& Candyce H. Williams Glaser. (2000). Use of Computer Technology to Help Students with Special Needs. The Future of Children, 10(2), 102-122. doi:10.2307/1602691

Hatzisavvidis, S. (2010). Grammar of New Greek Language. Theoretical bases and description. Thessaloniki: Vanias.

Horney, M. A., \& Anderson-Inman, L. (1999). Supported texts in electronic reading environments. Reading \& Writing Quarterly, 15, 127-168.

Keengwe, J., Schnellert, G. \& Mills, C. (2012). Laptop initiative: impact on instructional technology integration and student learning. Education and Information Technology. 17(2), 137-146.

Korat, O. \& Shamir, A. (2004). Do Hebrew electronic books differ from Dutch electronic books? A replication of a Dutch content analysis. Journal of Computer Assisted Learning, 20, 257- 268.

Kumar, A., Paek, T., \& Lee, B. (2012). Voice typing: a new speech interaction model for dictation on touchscreen devices. In Proceedings of the SIGCHI Conference on Human Factors in Computing Systems (CHI '12). ACM, New York, NY, USA, 2277-2286. DOI: http://dx.doi.org/10.1145/2207676.2208386

Massaro, D. W. (2004). Symbiotic Value of an Embodied Agent in Language Learning. In R.H. Sprague, Jr.(Ed.), Proceedings of 37th Annual Hawaii International Conference on System Sciences,(HICCS'04) (CD-ROM,10 
pages). Los Alimitos, CA: IEEE Computer Society Press. Best paper in Emerging Technologies.

Matsagouras, E. (2007). School literacy, Athens: Gregoris.

Moody, A. (2010). Using Electronic Books in the Classroom to Enhance Emergent Literacy Skills in Young Children, Journal of Literacy and Technology, 22 (11), 4.

Mponti, E. (2013). Special learning difficulties: an alternative approach for everyone. Thessaloniki: Methexis.

Novak J. D. (2010). Learning, Creating and Using Knowledge: Concept maps as facilitative tools and Corporations, Journal of e-learning and Knowledge Society, Vol. 6, p. 3, September 2010, pp. 21-30.

Panteliadou, S. \& Argyropoulos, B. (Eds). (2011). Special Education: from research to teaching. Athens: Pedio.

Pozzi, F. (2011). The impact of scripted roles on online collaborative learning processes. Computer-Supported Collaborative Learning, 6(3), p.471-474.

Stanford, P., \& Siders, J. A. (2001). Authentic assessment of intervention. Intervention in School and Clinic, 36(3), 163-167.

Tzivinikou, S. (2015). Learning difficulties - teaching interventions. Athens: Kallipos.

Vassiliou, M., \& Rowley, J. (2008), Progressing the definition of "e-book, Library

Hi Tech, Vol. 26 No. 3, pp. 355-68.

Walker, E., Rummel, N. \& Koedinger, R. (2011). Designing automated support to improve student helping behaviors in a peer tutoring activity. Computer-Supported Collaborative Learning. doi:10.1007/s11412-011-91112.

Zaid, M. A. (2011). Effects of web-based pre-writing activities on college EFL students' writing performance and their writing apprehension. Journal of King Saud University- Languages and Transition, 23 (2), pp. 77-85.

Zucker, T., Moody, A., \& McKenna, M. (2009). The Effects of Electronic Books on PreKindergarten-to-Grade 5 Students' Literacy and Language Outcomes: A Research Synthesis. Journal of Educational Computing Research, 40, 47-87. 